\title{
A Constituição de Corpos Guerreiros em um Currículo Escolar
}

\author{
Cristina d'Ávila Reis' \\ Marlucy Alves Paraíso'
}

'Universidade Federal de Minas Gerais (UFMG), Belo Horizonte/MG - Brasil

RESUMO - A Constituição de Corpos Guerreiros em um Currículo Escolar. Corpos guerreiros foram produzidos por meio de estratégias distintas em épocas e lugares diferentes. Neste trabalho, analisa-se a constituição de corpos guerreiros em um currículo escolar do ensino fundamental, tendo como base os referenciais teóricos da vertente pós-estruturalista dos estudos culturais e dos estudos queer. O argumento desenvolvido é o de que normas de gênero posicionam os corpos considerados meninos-alunos em diferentes níveis de normalidade e entrelaçam-se com uma tecnologia de ranking, de modo a produzir um ranking de gênero, no currículo pesquisado. Por meio desse ranking, corpos-meninos-alunos são posicionados em uma ordem de classificação quanto à força, coragem e agressividade, atributos guerreiros considerados masculinos.

Palavras-chave: Gênero. Currículo. Corpos Guerreiros.

ABSTRACT - The Constitution of Warrior Bodies in a School Curriculum. Warrior bodies were produced through several strategies at different times and places. This work analysis the constitution of warrior bodies in an elementary school curriculum based upon theoretical referentials of the post-structuralist branch of cultural studies as well as queer studies. The argument developed is the one that gender norms position the bodies considered boy-students at different levels of normality and also intertwine with a ranking tecnology, so as to produce a gender ranking in the researched curriculum. Through these procedures, boy-students are positioned in a ranking order according to strength, courage and aggressiveness, considered masculine warrior attributes.

Keywords: Gender. Curriculum. Warrior Bodies.

Educação \& Realidade, Porto Alegre, v. 38, n. 4, p. 1243-1266, out./dez. 2013.1243

Disponível em: <http://www.ufrgs.br/edu_realidade> 


\section{Introdução}

Todo herói tem uma escolha: ou enfrentar o mal, ou ser consumido por ele ${ }^{1}$.

Quantos amigos eu vi, ir morar com Deus no céu, sem tempo de se despedir, mas fazendo o seu papel ${ }^{2}$.

Verás que um filho teu não foge à luta, nem teme quem te adora a própria morte ${ }^{3}$.

Corpos guerreiros foram produzidos por meio de estratégias distintas em épocas e lugares diferentes. Guerra, instituições militares (Oliveira, 2004) e escolas (Castro, 1997; Sousa, 1994) têm sido importantes instâncias de produção desses corpos. Para a formação de futuros soldados em instituições escolares, atividades físicas e educação moral foram utilizadas no Brasil (Castro, 1997). No entanto, nem sempre o objetivo de formar guerreiros esteve registrado em documentos.

Entre o século XVII e a segunda metade do século XVIII, as disciplinas, que já existiam em conventos, exércitos e oficinas, generalizaram-se. Elas adentraram outros espaços, como uma anatomia política, como uma mecânica do poder (Foucault, 1987, p. 118) que "[...] define como se pode ter domínio sobre o corpo dos outros, não simplesmente para que façam o que se quer, mas para que operem como se quer, com as técnicas, segundo a rapidez e a eficácia que se determina" (Foucault, 1987, p. 119). Nessa época, o soldado, que anteriormente era reconhecido e escolhido entre os camponeses pelo que se considerava serem seus dotes naturais, passou a ser algo que se fabrica, por meio do controle calculado de sua postura, de seus gestos, de seus hábitos (Foucault, 1987).

Essa produção do corpo guerreiro esteve presente, também, no final do século XIX e início do século XX, quando a vida militar e a guerra foram pensadas e valorizadas como formas de modelar o corpo do homem, de desenvolver as habilidades de enfrentar a dor e o perigo, de estimular a coragem, o heroísmo e o sacrifício em prol de uma nação (Oliveira, 2004). Os exercícios físicos, que desde o século XVIII eram tidos como meios para desenvolver nos meninos força e vigor, durante o século XIX, tornaram-se "[...] cada vez mais comuns entre os jovens" (Oliveira, 2004, p. 61). No Brasil e em Minas Gerais, foi proposto o ensino da ginástica e dos exercícios militares para os meninos, nas escolas primárias dessa época, pois se entendia que eles seriam "[...] capazes de higienizar a sociedade, formando homens de corpo e caráter fortes, capazes de servirem à Pátria e à Família, dentro da ordem estabelecida" (Sousa, 1994, p. 28).

Esse ideal do guerreiro masculino foi também promovido intensamente, em vários países, após a Primeira Guerra Mundial, no século $\mathrm{XX}$, quando movimentos políticos como o nazismo, o fascismo e o socialismo russo valorizaram a força, a coragem, o heroísmo como im-

1244 Educação \& Realidade, Porto Alegre, v. 38, n. 4, p. 1243-1266, out./dez. 2013 Disponível em: <http://www.ufrgs.br/edu_realidade> 
portantes atributos para homens (Oliveira, 2004). Na década de trinta e quarenta do século XX, o objetivo de formar o futuro soldado esteve presente no pensamento educacional brasileiro (Sousa, 1994; Castro, 1997), e vários militares passaram a se encarregar das atividades físicas nas escolas (Castro, 1997). Seguindo essa orientação do governo federal brasileiro, o governo de Minas Gerais ampliou os espaços e horários destinados a atividades físicas nas escolas públicas primárias de Belo Horizonte (Sousa, 1994). O incentivo ao ensino militarista da educação física no País, nesse período, teve como finalidade, segundo Castro (1997, p. 23), “[...] fazer de cada corpo individual o corpo de um soldado, e com isso forjar o corpo da Nação”. A preocupação em formar corpos guerreiros nas escolas também pode ser vista, quando Sousa (1994) aborda a regulamentação de uma lei, pelo governo federal brasileiro, na década de 1960.

O governo Castelo Branco, na segunda metade da década de 60 , considerando que a maioria dos convocados para o serviço militar, em 1963, fora rejeitada, por ter sido considerada incapaz pelo exame de saúde, regulamentou o artigo 22 da LDB, mantendo a obrigatoriedade da Educação Física (Sousa, 1994, p. 156).

Assim, para a produção de corpos guerreiros, de corpos aptos ao serviço militar, a manutenção obrigatória da educação física nas escolas foi instituída pelo governo militar brasileiro, na década de sessenta. Na atualidade, tal demanda de formação de guerreiros não se encontra explícita em leis ou em documentos educacionais, como os Parâmetros e as Diretrizes Curriculares Nacionais. No entanto, estudos brasileiros que abordam temáticas de gênero nas escolas e nos currículos, na última década, analisaram como a força (Carvalhar, 2009; Dornelles, 2007; Ferrari, 2007), a agressividade (Carvalho, 2007; Dal'Igna, 2007; Dornelles, 2007) e a coragem (Carvalhar, 2009; Dornelles, 2007; Telles, 2004), consideradas atributos importantes para um guerreiro, em várias épocas e lugares (Oliveira, 2004), foram atribuídas àqueles que são vistos como meninos, de forma, muitas vezes, a naturalizar posições de sujeito culturalmente constituídas. Também em Belo Horizonte, no período de realização da pesquisa que deu origem a este trabalho, não esteve presente nas Proposições Curriculares para o $2^{\circ}$. Ciclo da Secretaria de Educação da Prefeitura Municipal o propósito de formar guerreiros. Apesar disso, posições de sujeito foram produzidas, em um currículo escolar, de modo a convocar aqueles considerados meninos-alunos a se constituírem como guerreiros.

Para a realização da pesquisa, utilizamos os referenciais teóricos da vertente pós-estruturalista dos estudos culturais e dos estudos queer. Desenvolvemos a pesquisa por meio da metodologia queer, com o uso de procedimentos etnográficos de coleta de informações e análise queer das informações coletadas. O trabalho de campo foi realizado junto

Educação \& Realidade, Porto Alegre, v. 38, n. 4, p. 1243-1266, out./dez. 2013.1245 Disponível em: <http://www.ufrgs.br/edu_realidade> 
a uma turma de vinte e três alunos/as do quarto ano do ensino fundamental - dezesseis considerados meninos, sete consideradas meninas - e doze profissionais de uma escola pública de Belo Horizonte.

Anteriormente ao trabalho de campo, o projeto de pesquisa foi submetido a um comitê de ética e foi aprovado. Os cuidados relativos a prestar informações, esclarecimentos aos/às participantes e aos/às responsáveis pelas crianças foram tomados antes e durante todo o desenvolvimento da pesquisa. Tanto os/as participantes como seus/suas responsáveis assinaram termos de consentimento, formalizando, assim, a aprovação da pesquisa.

Para a coleta das informações, foram realizadas observações registradas em diário de campo, consulta a documentos e conversas informais com alunos/as e profissionais da escola, durante um período de seis meses. Posteriormente, foi feita a análise queer das informações coletadas: um tipo de análise que enfoca, segundo Miskolci (2007), os processos de classificação, hierarquização e normalização dos sujeitos, de modo a problematizar o que é considerado "natural, estável e verdade" sobre eles (Souza; Carrieri, 2010, p. 65).

Analisamos, neste trabalho, como normas de gênero atuam em práticas curriculares pesquisadas, no entrelaçamento com uma tecnologia de ranking, de modo a constituir corpos-meninos-alunos que exacerbam características culturalmente consideradas masculinas como padrões ideais a serem atingidos. Argumentamos que normas de gênero posicionam os corpos considerados meninos-alunos em diferentes níveis de normalidade e entrelaçam-se com uma tecnologia de ranking, de forma a produzir um ranking de gênero no currículo pesquisado. Por meio da tecnologia de ranking, cada corpo é comparado a outros não apenas para que seja posicionado em relação a um padrão ideal, mas também para se produzir uma disputa constante entre os sujeitos por atingir uma posição à frente em uma ordem de classificação. Analisamos, assim, como o currículo investe na produção de posições de sujeito meninos-alunos em contínua busca por vencer, ir além dos limites, ser mais que, e como esse investimento se materializa na confluência com a materialização das normas de gênero para a formação de corpos guerreiros.

\section{Constituindo Corpos Guerreiros no Currículo}

Nas análises aqui realizadas, o currículo é compreendido como um campo cultural, em que diferentes discursos circulam e concorrem para os processos de subjetivação (Silva, 2006) e de materialização dos corpos. Os discursos produzem as posições com as quais os sujeitos podem se identificar (Woodward, 2000) e também produzem significados sobre os corpos (Butler, 2006). Os significados não são de autoria exclusiva de um sujeito que fala e age, mas são produzidos socialmente,

1246 Educação \& Realidade, Porto Alegre, v. 38, n. 4, p. 1243-1266, out./dez. 2013 Disponível em: <http://www.ufrgs.br/edu_realidade> 
culturalmente (Butler, 2009). Assim, significados produzidos em outros espaços, em outros campos culturais também podem estar presentes em um currículo, o qual não é, portanto, "senhor do que diz, [pois diz] sempre mais do que pretendíamos que dissesse, [faz] mais do que deveria fazer, [cria] o que não tínhamos previsto" (Corazza, 2001, p. 12). É com base nessa concepção de currículo que argumentamos, então, que corpos guerreiros são produzidos no currículo pesquisado.

A constituição de corpos guerreiros está presente em práticas discursivas cotidianamente produzidas e divulgadas sobre os corposmeninos-alunos. Diferentemente de outras épocas em que à escola era demandada explicitamente a formação do soldado, na época atual, corpos guerreiros são produzidos, sem que haja necessidade de propostas educativas formalizadas. Se a força, a agressividade e a coragem para combater, para enfrentar a dor foram atributos guerreiros considerados ideais a um corpo masculino em várias épocas (Oliveira, 2004), no currículo pesquisado, eles também são valorizados e divulgados por meio de variadas práticas em que meninos-alunos estão envolvidos na escola: constantes brincadeiras de lutas; brigas constantes na sala de aula, no pátio, na saída da escola; acesso a jogos de batalhas nas aulas de informática; predominância na escolha de jogos competitivos, que estimulam o desenvolvimento de habilidades guerreiras, durante as aulas de educação física e no recreio; além da presença de personagens masculinos que lutam, nas estampas de materiais escolares. Em todas essas práticas, o ideal do corpo masculino forte, corajoso e agressivo é divulgado e reiterado, convocando aqueles que são considerados meninosalunos a ocuparem a posição de sujeito menino-aluno-guerreiro. Assim, nos corredores, nos pátios e nas salas de aula essa posição é divulgada por atos cotidianos.

Bate o sinal do recreio. Crianças se levantam das cadeiras. Meninos-alunos se encontram dando empurrões, chutes e socos uns nos outros (Reis, 2011, p. 90).

José ${ }^{4}$ vai em direção à mesa do profissional da escola com o peito estufado e balançando os braços, demonstrando que é forte (Reis, 2011, p. 90).

Jorge e Leandro vão em direção ao armário da sala para procurar revistinha. Um bate o ombro no peito do outro. A batida vai crescendo em intensidade numa disputa por quem é mais forte (Reis, 2011, p. 91).

João fala para a profissional da escola que Pedro levantou da carteira. Pedro reage, estufando o peito e dizendo - Que levantei! Que levantei!

João volta para o seu lugar e diz - Tá dando uma de macho pra cima de mim... Ele vai ver! Vou dar um soco nele (Reis, 2011, p. 91).

Educação \& Realidade, Porto Alegre, v. 38, n. 4, p. 1243-1266, out./dez. 2013.1247 Disponível em: <http://www.ufrgs.br/edu_realidade> 
No recreio, meninos-alunos brincam de lutar. Chutam, empurram e enforcam os colegas, dão socos, jogam-se ao chão e deitam por cima dos colegas (Reis, 2011, p. 91).

Pelo uso de gestos agressivos ao se cumprimentarem, por atos de demonstração de força, ameaças de agressão e brincadeiras de lutas, meninos-alunos são convocados a ocuparem a posição de guerreiros. Para conformar a agressividade no corpo-menino-aluno, movimentos de lutas como boxe, capoeira, Kung Fu são divulgados.

Sérgio se levanta e simula golpes de capoeira em outros meninos. Profissional da escola olha para ele e ele volta para sua cadeira (Reis, 2011, p. 91).

Éder pula em frente ao Neimar que fala: Para de pular, fio. Vou mostrar um golpe procê de Kung Fu que vai desmaiar ocê rapidinho (Reis, 2011, p. 91).

Raul brinca de dar socos em Romeu, como se estivessem lutando boxe. Romeu cai e Raul o imobiliza no chão. Reginaldo vê a luta e vem correndo contar 3, 2,1, venceu Raul! (Reis, 2011, p. 92).

Mas essas brincadeiras de lutas, bastante divulgadas no currículo pesquisado, comumente se transformam no que eles/as chamam de porradão, que é a luta, a briga de verdade. O porradão ocorre, quando algum/a aluno/a envolvido/a na brincadeira atinge outro/a, em uma simulação de luta, ou machuca o/a outro/a propositadamente.

Observo as crianças no recreio. Meninos-alunos brincam de lutar. Muitas dessas brincadeiras se transformam em lutas de verdade, o que requer a intervenção de profissionais da escola que vigiam o recreio (Reis, 2011, p. 92).

Dois meninos-alunos brigam no recreio e várias crianças se juntam ao redor gritando - Uh! Porradã-ão! Uh! Porradã-ão! (Reis, 2011, p. 92).

Esse grito - “Uh! Porradã-ão!” - é usado comumente pelos/as alunos/as da escola pesquisada, em situações de briga. Aprender a dar e receber porradas é um aprendizado que faz parte do currículo pesquisado: socos, chutes, enforcamentos, rasteiras, imobilizações, lançamento de objetos nos/as colegas são práticas constantes que constituem o corpo-menino-aluno, como aquele que briga muito.

Na hora do recreio, vejo uma profissional da escola com o lanche na mão e correndo aflita de um lado para o outro para resolver brigas entre as crianças. A maioria das brigas que acontece é entre meninos-alunos. Digo pra ela:

- Nem tempo pra lanchar você tem?

Ela responde - É... esses meninos me deixam doida! (Reis, 2011, p. 92).

1248 Educação \& Realidade, Porto Alegre, v. 38, n. 4, p. 1243-1266, out./dez. 2013 Disponível em: <http://www.ufrgs.br/edu_realidade> 
O ideal normativo de um corpo masculino forte, corajoso e agressivo também está presente em um site acessado por meninos-alunos, nas aulas de informática ${ }^{5}$, onde os jogos são anunciados com as seguintes frases - "Atire sem dó em todos os paraquedistas" - "Acerte inimigos do alto de um prédio" - "Defenda a fortaleza do ataque inimigo" - "Bata em todo mundo e ganhe uma grana”.

Na relação e em oposição a esse corpo masculino forte e agressivo, a posição de quem apanha também é constituída. "Lina - A gente não gosta de menino que bate muito não. A gente prefere brincar com menino que bate pouco" (Reis, 2011, p. 93).

A posição de sujeito menina-aluna-que-apanha é assim constituída como alguém que tem que optar por apanhar mais ou apanhar menos. $\mathrm{O}$ ato de bater no/a colega está tão naturalizado como próprio de meninos-alunos, que as opções de escolha para quem convive com aqueles que ocupam a posição menino-aluno-guerreiro são: brincar com o menino-aluno que bate muito ou brincar com o menino-aluno que bate pouco.

Para Butler (2006), é por meio de atos corporais reiterados, de fala ou não, que as normas de gênero são divulgadas, mantêm-se e podem ser alteradas. Por meio da reiteração dos atos acima mencionados, portanto, a posição de sujeito menino-aluno-guerreiro é constituída. Ser forte, agressivo e corajoso é o que se produz como homogêneo para o corpo social meninos-alunos, no currículo pesquisado. No entanto, além de ser produzida a homogeneidade de um corpo social (Foucault, 1987) pela norma, a individualização também é produzida, “[...] por medidas comparativas que têm a 'norma' como referência” (Foucault, 1987, p. 160). A individualização com relação aos atributos guerreiros é produzida por meio da atuação conjunta de normas de gênero e de uma tecnologia de ranking, que operam de modo a ordenar os corpos-meninos-alunos e colocá-los em relação como mais guerreiros que ou menos guerreiros que.

\section{Do Menos Guerreiro ao Mais e Sempre Mais Guerreiro- Menino}

Ranking da Copa do Mundo, das Olimpíadas, do mercado mundial, da habilidade nos jogos em programas televisivos, dos corpos nos Relatórios Guinness, de filmes nos festivais de cinema. Ranking de desempenho dos/as alunos/as e das escolas no Exame Nacional do Ensino Médio (ENEM), na Prova Brasil, na Prova Avalia BH, no Índice de Desenvolvimento da Educação Básica (IDEB), nos campeonatos esportivos entre escolas, nas olimpíadas de matemática e de língua portuguesa, nos concursos de redações, de desenhos. Ranking de notas dos programas de pós-graduação, de avaliação das revistas científicas, da produção acadêmica de artigos, da qualidade de teses... Um mecanismo ranqueador anda à solta.

Educação \& Realidade, Porto Alegre, v. 38, n. 4, p. 1243-1266, out./dez. 2013.1249 Disponível em: <http://www.ufrgs.br/edu_realidade> 
A Constituição de Corpos Guerreiros em um Currículo Escolar

É possível entender esse mecanismo ranqueador, quando Ehrenberg (2010) descreve a disseminação de um estilo esportivo e empreendedor de ser, que ultrapassa o mundo do esporte e da empresa e se infiltra em outros setores da vida social ${ }^{6}$. Competir, ultrapassar limites, enfrentar riscos e desafios em situações de mudança e imprevisibilidade, agir com responsabilidade e autonomia, como um empreendedor de si mesmo tornam-se as novas normas que orientam as condutas individuais (Ehrenberg, 2010). Para Gadelha (2009, p. 151), a governamentalidade própria ao capitalismo contemporâneo busca controlar os sujeitos “[...] em suas formas de agir, sentir, pensar e de situar-se diante de si mesmos”, por meio de processos de subjetivação que fazem “[...] dos princípios econômicos (de mercado) os princípios normativos de toda a sociedade" (Gadelha, 2009, p. 151). Segundo esse autor, os sujeitos são induzidos a cada vez mais estabelecerem entre si relações de concorrência (Gadelha, 2009, p. 151).

\begin{abstract}
Os indivíduos e as coletividades vêm sendo cada vez mais investidos por novas tecnologias e mecanismos de governo que fazem de sua formação e de sua educação, num sentido amplo, uma espécie de competição desenfreada, cujo "progresso" se mede pelo acúmulo de pontos, como num esquema de milhagem, traduzidos como índices de produtividade (Gadelha, 2009, p. 156).
\end{abstract}

Índices de produtividade são calculados, classificados, ordenados. Os corpos são cada vez mais pensados e dispostos em uma ordem de habilidades que os define como melhores ou piores que outros, mais respeitáveis ou menos respeitáveis, mais normais ou menos normais, de modo a induzi-los a uma permanente busca por atingir posições à frente na ordem de classificação. Essa forma de classificá-los, de ordená-los não é produzida apenas por organismos governamentais, por empresas, mas se encontra disseminada por todo o tecido social, como um modo de pensar e de organizar as práticas cotidianas, como uma racionalidade que produz desejos, emoções, ações e que convoca os sujeitos, como diz Ehrenberg (2010), a cada vez mais querer vencer, ir além dos limites.

Em associação a essa competição desenfreada (Gadelha, 2009) ou ao estilo esportivo e empreendedor de ser (Ehrenberg, 2010), entendo, então, que um mecanismo ranqueador é acionado para governar os corpos. O governo dos corpos é compreendido, nas análises aqui realizadas, como uma forma de poder que se exerce por meio de mecanismos e procedimentos que visam conduzir a conduta dos seres humanos (Foucault, 1993). Com base em Rose (2001, p. 38), os meios de “[...] governar os seres humanos, [de] moldar ou orientar [suas condutas]" são entendidos como técnicas. É a atuação no currículo pesquisado de um conjunto de técnicas de ranking, que analiso a seguir.

Conversando com Renan, um dos/as alunos/as da turma observada, sobre o que ele acha da escola, ele me diz que

1250 Educação \& Realidade, Porto Alegre, v. 38, n. 4, p. 1243-1266, out./dez. 2013. Disponível em: <http://www.ufrgs.br/edu_realidade> 
o problema é que os meninos ficam "enchendo o saco um do outro". Pergunto a ele se os meninos enchem o saco dele e ele me diz que não, porque, segundo Renan, os meninos têm medo dele. Pergunto por que e ele me diz que é porque ele é o mais forte da turma. Depois ele diz - O Sinval é o segundo, depois é o Lenilson, o Fernando, o Jorge, o Cleber, o João... O João bate só no Jonas, no Hilton, no Neilton e no Carlos - Pergunto sobre o Olavo, um menino-aluno que é constantemente chamado de mulherzinha por muitas crianças da turma e ele me responde - O Olavo ninguém gosta dele - Pergunto: em que lugar o Olavo está? Renan responde - O último. É o mais fraco da sala toda (Reis, 2011, p. 96).

Enunciações como essas, que classificam corpos e os posicionam em ordem de habilidades, estão presentes no currículo pesquisado. São enunciações que avaliam os corpos, utilizando um padrão ideal como medida de comparação. No caso acima, ser forte é o padrão atribuído aos meninos-alunos. É o que se produz como homogêneo para o corpo social meninos-alunos. Para Foucault (1987), o poder de regulamentação estabelece a homogeneidade a um corpo social, mas também individualiza. Dentro “[...] de uma homogeneidade que é a regra [o poder da norma] introduz, como um imperativo útil e resultado de uma medida, toda a gradação das diferenças individuais." (Foucault, 1987, p. 154). É assim que, no currículo pesquisado, os corpos meninos-alunos são classificados, hierarquizados e posicionados em uma ordem de diferenças individuais com relação a várias características, dentre elas, a força física.

Se as normas de gênero constituem de maneira dicotômica os corpos masculinos e femininos, se produzem a anormalidade daqueles que não se enquadram nesses padrões culturais por elas divulgados (Butler, 2006), elas também produzem ordens de normalidade para cada gênero ${ }^{7}$. Assim, características culturalmente consideradas masculinas são produzidas como um ideal a ser conquistado por corpos tidos como homens, um ideal que produz a maior normalidade e a maior valorização social daquele corpo que dele mais se aproxima. No currículo pesquisado, o ideal do corpo-menino-forte atua de modo a posicionar como normais, como meninos-alunos, os corpos que são tidos como fortes e como anormais, como meninos-alunos-mulherzinhas, os que são tidos como fracos. Entretanto, esse ideal normativo atua, também, de maneira a posicionar os corpos como mais normais ou menos normais, mais respeitáveis ou menos respeitáveis, de acordo com o grau de aproximação em relação a ele. Enunciações presentes no fragmento do diário de campo anterior explicitam essa ordenação dos corpos com relação à característica força física: o corpo mais forte é aquele mais respeitado, que ninguém o incomoda; depois vem o segundo mais forte, o terceiro mais forte, até chegar àquele que, segundo Renan, "ninguém gosta dele", no menino-aluno que é constantemente chamado de mulherzinha.

Educação \& Realidade, Porto Alegre, v. 38, n. 4, p. 1243-1266, out./dez. 2013.1251 Disponível em: <http://www.ufrgs.br/edu_realidade> 
A Constituição de Corpos Guerreiros em um Currículo Escolar

O posicionamento dos corpos em relação a um padrão ideal, como o descrito acima, é produzido em um campo atravessado por relações de poder. Essas relações têm se estabelecido de modo a produzir uma maior valorização social dos heterossexuais e dos corpos considerados masculinos (Butler, 2003). No entanto, problematizamos aqui, também, a produção de “[...] gradações de diferenças individuais” (Foucault, 1987, p. 154), de níveis de normalidade e de valor atribuídos aos próprios corpos considerados do sexo masculino. Essas diferenças de normalidade e de valoração dos corpos são produzidas por meio da atuação conjunta de normas de gênero e de uma tecnologia de ranking. $\mathrm{O}$ ranking, como tecnologia de governo, atua como uma forma de pensar sobre os corpos, de se relacionar com eles, de dispô-los em uma ordem de habilidades, disseminada por todo tecido social; uma forma que os convoca ao constante desejo por atingir uma posição à frente na ordem de classificação. Essa tecnologia, associada a normas de gênero, produz o que Gadelha (2009) entende por competição desenfreada. Uma competição desenfreada por ser mais guerreiro é produzida no currículo, divulgando o ímpeto por se tornar mais agressivo, mais corajoso e mais forte como características naturais daqueles que são designados homens e meninos.

Para entender a relação entre o que o Estado e o mercado demandam e a maneira como a tecnologia de ranking atua, é necessário compreender, também, o conceito de governo, tal como utilizado em alguns estudos foucaultianos. O governo abrange "[...] programas e estratégias mais ou menos racionalizados para a 'conduta da conduta'” (Rose, 2001, p. 41). Formas de racionalidade política organizam práticas, que podem ser pensadas “[...] em termos de 'técnica' ou 'tecnologia”” (Castro, 2009, p 412). Direcionadas "[...] por um objetivo mais ou menos consciente" (Rose, 2001, p. 38), as “[...] tecnologias humanas são montagens híbridas de saberes, instrumentos, pessoas, sistemas de julgamento, edifícios e espaços, orientados, no nível programático, por certos pressupostos e objetivos sobre os seres humanos" (Rose, 2001, p. 38). O ranking da força, da agressividade e da coragem, que é produzido no currículo pesquisado, atua, portanto, como uma tecnologia de governo que, em associação com normas de gênero, opera de modo a convocar aqueles que são considerados meninos-alunos a se tornarem cada vez mais guerreiros. Variadas técnicas atuam para constituir corpos masculinos cada vez mais guerreiros. Analiso, aqui, as técnicas de ordenação dos corpos: mental, territorial, pela apropriação de recursos, esportiva, a técnica de abjeção aos fracos e pouco agressivos e a técnica de enaltecimento do guerreiro urbano.

Na prática curricular apresentada no primeiro fragmento de diário de campo deste tópico, a ordenação mental dos corpos se faz presente. Essa técnica atua como um modo de pensar, de avaliar a si mesmo e os outros, posicionando mentalmente os corpos em ordens de habilidades, de maneira a produzir o desejo por atingir uma posição à fren-

1252 Educação \& Realidade, Porto Alegre, v. 38, n. 4, p. 1243-1266, out./dez. 2013. Disponível em: <http://www.ufrgs.br/edu_realidade> 
te na ordem constituída. Na prática curricular citada, Renan avalia a si mesmo e posiciona-se como o mais forte da turma. Ao mesmo tempo em que é produzido um saber sobre si mesmo, baseado no ideal normativo do corpo masculino forte, um saber sobre os corpos de seus colegas também é produzido, de modo a posicioná-los em uma ordem, do mais forte ao mais fraco. O ranking de gênero é, então, estabelecido na forma como cada um pensa e avalia a si mesmo em relação aos outros/ as e, concomitantemente, pensa e avalia os/as outros/as em relação a si. Técnica de si e técnica de dominação ${ }^{8}$ atuam conjuntamente para a ordenação valorativa dos corpos masculinos - do mais forte meninoaluno-guerreiro ao mais fraco, que é aquele considerado mulherzinha pelos/as colegas.

Outra técnica presente no currículo pesquisado é a ordenação territorial dos corpos, a qual opera na prática curricular do recreio. $\mathrm{O}$ recreio é um horário da rotina escolar em que os/as alunos/as ficam nos pátios, sob os cuidados de alguns/mas profissionais da escola. Sua produção como algo desejado pelas crianças está presente na eficácia da ameaça aos/às alunos/as de ficarem sem essa atividade.

Profissional da escola - Nós não descemos para a aula de educação física... Tô começando a desconfiar que a gente não vai descer pro recreio. Não aceito essa barulhada. Alunos/as fazem silêncio (Reis, 2011, p. 100).

Se por um lado o recreio é entendido como algo prazeroso para os/as alunos/as, por outro ele não é mencionado nas Proposições Curriculares para o Segundo Ciclo da Prefeitura de Belo Horizonte como atividade educativa. Essa produção de significados sobre o recreio, que o constitui como espaço de lazer apenas, faz dele um instrumento tático efetivo nos processos de subjetivação relacionados a gênero. Como discurso que tem efeito de verdade no currículo, ele organiza práticas cotidianas, como a de escalar menos profissionais da escola para acompanhar os/as alunos/as nos pátios que os profissionais que ficam em sala de aula: dois/duas ficam nas portas que separam o prédio escolar dos pátios, controlando a entrada e a saída de alunos/as e dois/duas ou três permanecem nos pátios para cuidar dos/as alunos/as de todas as turmas. Como espaço de menor presença de profissionais da escola, o recreio é constituído, assim, como uma importante prática de produção de um ranking de gênero, por meio da qual são constituídos corpos-meninos em busca por se tornarem cada vez mais guerreiros.

Esse ranking se faz visível na atuação da técnica de ordenação territorial dos corpos-meninos-alunos. Por meio dessa técnica, os corpos são posicionados territorialmente em uma ordem de habilidades guerreiras consideradas masculinas: os meninos-alunos considerados mais guerreiros mantêm-se mais distantes do prédio da escola, na quadra coberta, que é considerada a melhor; depois tem a quadra descoberta, que é ocupada pelos meninos-alunos menos guerreiros e, assim sucessivamente, até chegar ao espaço próximo à cantina e ao prédio da esco-

Educação \& Realidade, Porto Alegre, v. 38, n. 4, p. 1243-1266, out./dez. 2013. 1253 Disponível em: <http://www.ufrgs.br/edu_realidade> 
la, que é mais ocupado por aqueles/as que são menores e que apresentam menores habilidades guerreiras. Já para os que são considerados meninos-alunos-mulherzinhas, parece não haver um lugar nos espaços reservados ao recreio, quando a fuga do pátio se torna algo constante. Eles ficam pelos corredores, andando de um lado para outro, burlando a regra escolar de que todos/as devem permanecer nos pátios ou, quando não conseguem fugir, permanecem, muitas vezes, nas arquibancadas.

Encontro com Osmar, que é chamado constantemente de mulherzinha pelos/as colegas, no corredor da escola, na hora do recreio. As outras crianças da turma estão no pátio. Pergunto a ele:

- Você não vai para o pátio?

Ele faz não com a cabeça.

- O que você está fazendo?

- Lendo livrinho.

Ele está com uma revistinha na mão. Depois disso, uma profissional da escola o vê e diz que ele não pode ficar ali. Ele caminha em direção ao pátio e, quando a profissional da escola vira as costas, ele volta escondido. Essa é a segunda vez que o vejo fugir do pátio (Reis, 2011, p. 101).

Assim, meninos-alunos considerados como tendo maiores habilidades guerreiras, como força, agressividade e coragem, definem os espaços que irão utilizar, criando seus próprios territórios e deixando para os menos guerreiros espaços considerados piores. Quando estão longe dos/as profissionais que tomam conta do recreio, os considerados mais guerreiros constantemente ocupam os espaços que desejam e, também, utilizam os equipamentos e materiais disponibilizados da maneira como decidem.

No recreio, meninos-alunos fazem fila no bebedouro. Um menino chega à frente de todos, dá um chute no bebedouro e diz - Agora sou eu.

Ninguém se opõe, a não ser Cirilo, que seria o próximo a beber água. Cirilo não o deixa passar à frente. $\mathrm{O}$ meninoaluno pega Cirilo pelo pescoço, enforcando-o. Nenhuma outra criança que estava na fila ajuda Cirilo ou enfrenta aquele que se mostra mais forte. O menino-aluno toma água e manda todos os outros passarem à frente de Cirilo. Um por um, os meninos-alunos vão passando à frente $\mathrm{e}$ tomando água, sob o comando do mais forte. Cirilo reclama e o menino-aluno mais forte o empurra. Cirilo cai. O menino-aluno o ameaça agredir mais e eu entro no meio dos dois ${ }^{9}$ (Reis, 2011, p. 101).

Vítor fala com lágrimas nos olhos: Sacanagem o que aquele menino fez com o André. O André que levou a bola e ele chegou tomando a bola do André e batendo nele. Os menino mais velho não respeita a gente não (Reis, 2011, p. 101).

Túlio volta do recreio chorando e uma profissional da escola pergunta o que é que aconteceu.

1254 Educação \& Realidade, Porto Alegre, v. 38, n. 4, p. 1243-1266, out./dez. 2013. Disponível em: <http://www.ufrgs.br/edu_realidade> 
Túlio - Eu ia montar meu time, porque eu cheguei primeiro e aí ele falou: não, você não vai montar seu time não. Aí eu falei: mas eu que cheguei primeiro. E aí ele me bateu. Depois Jorge me contou que Túlio foi falar o que ocorreu com o coordenador. O coordenador mandou Túlio chamar o menino que tinha batido nele para conversar. Quando Túlio foi chamá-lo, o menino bateu nele novamente (Reis, 2011, p. 101).

Apesar da regra elaborada pelas próprias crianças de que quem chega primeiro na quadra e quem tem a posse da bola tem direito a jogar e escolher o time de futebol, os meninos-alunos considerados mais fortes agridem os tidos como mais fracos, roubam-lhes a bola e frequentemente ocupam a quadra. Apesar da regra de prioridade de uso dos equipamentos para quem chega primeiro, são os considerados mais guerreiros, ou seja, os mais fortes, mais agressivos e mais corajosos que decidem, muitas vezes, quem usa o que e em qual ordem de uso. Uma técnica de ordenação territorial dos corpos atua, nessas práticas, portanto, juntamente com uma técnica de ordenação dos corpos pela apropriação de recursos para a produção de um ranking de gênero.

Embora os/as coordenadores/as sejam diariamente requisitados/ as para resolver conflitos relacionados ao uso de espaços, equipamentos e materiais, não é todo conflito que se resolve na coordenação. $\mathrm{O}$ recreio funciona, assim, como um espaço de produção de um ranking de gênero, de um posicionamento de corpos meninos-alunos em uma ordem de habilidades guerreiras consideradas masculinas, que os estimula a tornarem-se cada vez mais guerreiros para conseguirem fazer e utilizar o que desejam.

Outra prática curricular de produção de um ranking de gênero, no currículo pesquisado, é o jogo de ranca, um tipo de jogo de futebol em que um joga a bola para o outro, tentando acertá-lo. Aquele, no qual a bola encosta, perde o jogo e é atacado com chutes por todos os outros. Participam desse jogo, no recreio, apenas os meninos-alunos da turma que são vistos como mais corajosos. Quando percebem que o jogo começou, algumas crianças saem do campo de futebol correndo e gritando - “É ranca! É ranca!" Quando um profissional da escola passa por perto, eles voltam a jogar o futebol comum. Flávio, uma das crianças da turma pesquisada, disse: "tem que ser corajoso pra jogar esse jogo".

Prática semelhante entre crianças de uma escola pública é analisada por Ferrari (2007). Esse autor descreve uma brincadeira semelhante à ranca, denominada loba (Ferrari, 2007, p.04). A participação no jogo loba, segundo o autor, define os que são vistos como "[...] verdadeiros homens" (Ferrari, 2007, p. 14). Também no jogo ranca, aquele que participa é mais valorizado como menino, por se mostrar mais corajoso. Não basta, porém, ser apenas corajoso; tem também que ser forte e agressivo para chutar aquele que perde. Também não é suficiente pouca agressividade; tem que ser o mais agressivo possível. É assim que um menino-

Educação \& Realidade, Porto Alegre, v. 38, n. 4, p. 1243-1266, out./dez. 2013. 1255 Disponível em: <http://www.ufrgs.br/edu_realidade> 
aluno sai da quadra de futebol, vai até a arquibancada de outro pátio, onde está um grupo de crianças, e diz sorridente que desmaiou ${ }^{10} \mathrm{um}$ colega.

Para Foucault (2006), os sujeitos não são seres sobre os quais o poder atua apenas para tolher suas ações, seus desejos, suas formas de ser, mas desejos e maneiras de ser são constituídos em meio a relações de poder. (Foucault, 2006). É assim que a alegria por desmaiar o colega é produzida por uma técnica esportiva. Se a força, a agressividade e a coragem para agredir um colega são prescritas a um corpo-meninoaluno por normas de gênero, a busca por atingir uma posição à frente na ordem de classificação de atributos guerreiros é efeito dessa técnica esportiva, que produz a exacerbação da agressividade, da força e da coragem, como algo desejável. Por meio dessa técnica, que atua concomitantemente como técnica de dominação e como técnica de si, corpos-meninos-alunos são posicionados e se posicionam em uma ordem de classificação esportiva, que os incita a tornarem-se cada vez mais guerreiros para vencerem o jogo.

É a exacerbação da agressividade, da força e da coragem que também é divulgada pelos significados produzidos sobre o corpo bad boy, divulgado em letras de músicas ${ }^{11}$ e em site de venda de produtos para homens e meninos na internet ${ }^{12}$. Imagens de homens musculosos e com expressão agressiva aparecem estampadas em roupas, uniformes de luta, materiais escolares, revista em quadrinhos. Enunciações como - "O homem mais forte das Américas"13 - "Eu me encontrei através da luta. Meu maior objetivo é ser campeão"14 - são divulgadas de modo a constituir o corpo-bad-boy como aquele que é muito forte, corajoso e agressivo. Esses atributos também são valorizados em dois comerciais de armas de brinquedo veiculados em 2010. Nesses comerciais, concomitantemente às imagens de meninos empunhando armas e lançando dardos, um homem diz, entre outras coisas - "Você pode derrotar seu inimigo com três dardos por segundos ou recorrer à munição extra para sua total cobertura" - "É só mirar e atingir o impossível" - "O lançador com maior capacidade de dardos" - "É mais poder de ataque"15.

Atacar mais, ser um campeão na luta, atingir o impossível, desmaiar o colega é ponto para quem está guerreando, para quem é convocado a ser mais guerreiro. A técnica de ordenação esportiva, que produz o desejo por se tornar mais guerreiro, não atua apenas nos esportes e jogos propriamente ditos mas também nas pequenas disputas cotidianas, no currículo pesquisado.

Otávio conta para Túlio que quebrou o nariz do irmão mais velho e que ele teve que ir para o hospital. Túlio faz uma expressão de que não acredita e Otávio diz, demonstrando orgulho - Sério! Quebrei o nariz dele! (Reis, 2011, p. 104).

Bruno e Ricardo disputam quem machuca o outro. Bruno - Chuta!

1256 Educação \& Realidade, Porto Alegre, v. 38, n. 4, p. 1243-1266, out./dez. 2013. Disponível em: <http://www.ufrgs.br/edu_realidade> 


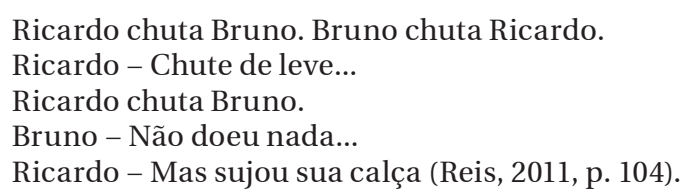

Machucar o outro é ponto para quem guerreia. Entretanto, se o objetivo de machucar o colega não é atingido, sujar a calça dele já serve, pois, destruir de alguma forma o oponente é objetivo daquele que joga o jogo de ser guerreiro. Na disputa por quem mais ataca, nos atos de apanhar e bater no outro, de destruir o outro, algo mais se faz necessário: a coragem para machucar ou infligir dor ao outro e para enfrentar a própria dor. É assim que a valorização dos atos de atacar o outro e de oferecer seu próprio corpo para ser chutado por outra pessoa, como no jogo de ranca, faz parte da formação de guerreiros corajosos, pela técnica de ordenação esportiva.

Além das técnicas de ordenação dos corpos-meninos-alunos, de acordo com os atributos guerreiros, a abjeção àqueles que são considerados fracos e pouco agressivos também opera, no currículo, como técnica para constituir corpos-meninos-alunos cada vez mais guerreiros. Para Butler (2006), as normas de gênero produzem a abjeção daqueles corpos que não se enquadram em um dos polos - homem ou mulher, masculino ou feminino. O corpo abjeto é aquele que não se encaixa nos padrões de inteligibilidade cultural para o gênero e que, por isso, é visto como menos humano, é tido como sem valor (Butler, 2006). No currículo pesquisado, a abjeção àqueles que são considerados pouco fortes e pouco agressivos é produzida como técnica para governar os corposmeninos-alunos, incitando-os a se tornarem cada vez mais guerreiros. Essa técnica atua de forma a associar a pouca agressividade e pouca força às posições de sujeito menino-aluno-bichinha ou menino-alunomulherzinha, ao mesmo tempo em que as constitui como posições de menor valor. Assim, abaixo dos meninos-alunos considerados normalmente guerreiros no ranking de gênero, é constituída a posição de sujeito menino-aluno-bichinha.

Pesquisadora - Agora me conta aqui uma coisa: Uma vez, eu lembro que você me falou que tem outro menino que é bicha, de outra turma... E você me disse que ele é bicha porque ele gosta de brigar de tapinha...

Joel - Ah é o... esqueci o nome dele é o...Jader!

Pesquisadora - Isso. Então quem é bicha briga de tapinha... e quem não é bicha briga como?

Joel - Quem não é bicha briga diferente, ué. Tapinha não é coisa de mulher? Mulher não briga assim?

Pesquisadora - Tapinha é coisa de mulher. E coisa de homem como é que é?

Joel - Ah, soco, chute, essas coisas, atropelado (Reis, 2011, p. 106).

A posição menino-aluno-bichinha é constituída, então, como a daquele menino-aluno que briga como mulher, por meio de atos agres-

Educação \& Realidade, Porto Alegre, v. 38, n. 4, p. 1243-1266, out./dez. 2013. 1257

Disponível em: <http://www.ufrgs.br/edu_realidade> 
sivos considerados menos potentes: os tapinhas. Abaixo dessa posição, no ranking de gênero, é produzida, ainda, a posição de sujeito meninoaluno-mulherzinha, como a daquele que não reage a agressões e que é diferente dos outros por não ser tão agressivo.

Pesquisadora - E por que eles chamam o Nelson de mulherzinha?

Profissional da escola - É somente pra zoar, porque acham o Nelson estranho. Como eles não sabem definir que tipo de estranho que é, eles chamam de mulherzinha. "Ele não fala, deixa tomar a maçã dele, deixa tomar a merenda dele, só fica chorando, chorando" (Imita as crianças falando). Ele ficava paradinho com a merenda assim ó (Imita o gesto de segurar a merenda à frente do corpo com as mãos no ar). E aquelas merendas gostosas, diferentes. Aí os meninos passavam e tomavam. E ele continuava assim, ó - Imita o gesto - e chorando. Aí eu chegava: O que é que foi? "Os menino passou aqui correndo e tomou minha merenda." - Imita o Nelson falando. Aí uns mais maldosos riam daquele ato e diziam que ele não enfrentava, ele só chorava e... deduziam isso (Reis, 2011, p. 106).

Profissional da escola - Os meninos, a turma em geral, se não houver uma intervenção, sempre há uma tendência a hostilizar quem chega com um jeito diferente, se apresenta com uma forma de falar diferente ou mesmo de interagir que não é tão agressiva, né? O Túlio é um menino muito tranquilo (Reis, 2011, p. 106).

Assim, ser pouco agressivo, agredir como uma mulher e não reagir a agressões são características atribuídas àqueles meninos-alunos que são vistos como diferentes. As posições de sujeito menino-alunomulherzinha e menino-aluno-bichinha são constituídas, então, como posições que produzem a hostilização e crítica àqueles que as ocupam, por não manifestarem adequadamente as habilidades guerreiras consideradas masculinas. É, portanto, por meio da técnica de abjeção aos meninos-alunos que ocupam essas posições que o poder atua de forma estratégica para produzir o desejo por se tornar mais guerreiro.

Outra prática de produção de um ranking de gênero no currículo pesquisado é a circulação de discursos do crime. Esses discursos são divulgados, no currículo, por meio da referência a jogos que são utilizados pelos/as alunos/as, em casa, como pode ser visto a seguir.

Uma profissional da escola solicita às crianças para contarem aos colegas o que fizeram nas férias. Jarbas responde que jogou GTA $4^{16}$ (Reis, 2011, p. 107).

Descrito como um jogo em que “[...] o criminoso protagonista (o avatar) pode, além de roubar, matar, agredir e transgredir as leis e normas sociais em ambientes urbanos" (Abath; Carvalho, 2010, s. p.), o GTA 4 envolve frequentes atos agressivos e combates constantes do

1258 Educação \& Realidade, Porto Alegre, v. 38, n. 4, p. 1243-1266, out./dez. 2013 Disponível em: <http://www.ufrgs.br/edu_realidade> 
criminoso com policiais que o perseguem. Tal como um guerreiro urbano em busca do que deseja para si, ele rouba carros, armas e outros bens. Quanto mais ele guerreia e rouba, mais pontos ganha quem está jogando. O enunciado, divulgado por meio desse jogo, de que uma pessoa deve lutar e praticar crimes para conseguir o que deseja, também é divulgado por meio de uma música cantada por duas crianças, em tom baixo, durante atividade de desenho em duplas, na sala de aula.

\begin{abstract}
Hélder e Sávio cantam - Na faixa de gaza, só homem bomba, na guerra é tudo ou nada, várias titânio no pente, colete a prova de bala. Nós desce pra pista pra fazer o assalto, mas tá fechadão no doze. Se eu tô de rolé, seiscentos bolado, perfume importado, pistola no bolso. Mulher, ouro e poder, lutando que se conquista. Nós não precisa de crédito, nós paga tudo a vista. É Ecko, Lacoste, é peça da Oakley, várias camisas de time. Quem tá de fora até pensa que é mole viver do crime. Nós planta humildade, pra colher poder. A recompensa vem logo após. Não somos fora da lei, porque a lei quem faz é nós. Nós é o certo pelo certo, não aceita covardia. Não é qualquer um que chega e ganha moral de cria. Quantos amigos eu vi, ir morar com Deus no céu, sem tempo de se despedir, mas fazendo o seu papel $[. . .]^{17}$. - Depois de repetirem a música por três vezes, pergunto a eles que música é essa. Hélder me diz que é Faixa de Gaza. Pergunto de quem é a música e Sávio me diz que é música de bandido. Ele diz que no Youtube tem um cara com duas metralhadoras, cantando essa música (Reis, 2011, p. 107).
\end{abstract}

Nas enunciações acima, a batalha pela sobrevivência é divulgada como uma guerra, tal qual um campo de batalha entre exércitos. $\mathrm{O}$ guerreiro urbano é visto como alguém que vive do crime, mas que é recompensado. Na luta pela conquista de bens materiais, por posições de maior status, por mulheres, o guerreiro urbano faz sua própria lei, não pode ser covarde: faz o que lhe é destinado, mesmo correndo o risco de morrer. Contudo, para ser valorizado, não pode ser um guerreiro qualquer, pois “[...] não é qualquer um que chega e ganha moral de cria”. Por meio da técnica de enaltecimento do guerreiro urbano, esse discurso presente no currículo pesquisado convoca meninos-alunos a se tornarem mais fortes, corajosos e agressivos. Ela atua pela divulgação de um ideal do guerreiro corajoso, que corre risco de morte, que luta muito e pratica crimes para conseguir o que deseja.

Visto como um corpo que não é produzido pelo currículo escolar, o menino-aluno-guerreiro é também percebido como assustador, como algo que preocupa.

Profissional da escola - Eu fiquei assustada logo que entrei nessa sala de aula. Eu pensei: daqui uns dias esses meninos estão batendo no professor! (Reis, 2011, p. 108).

Educação \& Realidade, Porto Alegre, v. 38, n. 4, p. 1243-1266, out./dez. 2013.1259 Disponível em: <http://www.ufrgs.br/edu_realidade> 
A Constituição de Corpos Guerreiros em um Currículo Escolar

Profissional da escola - Briguinhas, sempre vão acontecer, a gente é ser humano, faz parte, isso é normal mesmo. Entende? A questão é o excesso. Esse é que é o problema, né? O excesso (Reis, 2011, p. 108).

Os menino briga muito. Briga muito por causa de coisa boba. Fala assim... Se a gente chama eles de... de um palavreado ruim, eles vão lá e briga (Reis, 2011, p. 108).

Profissional da escola - A situação de violência tem aumentado muito. A escola não pode simplesmente ser uma reprodutora dessa violência (Reis, 2011, p. 108).

O corpo menino-aluno-guerreiro é constituído, então, como assustador, como aquele que é fruto do aumento da violência. São esses significados que também são produzidos para alunos adolescentes, descritos em uma reportagem fixada no quadro de avisos, na sala dos/ as professores/as.

Em um dia de aula como outro qualquer, Helena ${ }^{18}$ passou a integrar um contingente que cresce a cada dia, em um drama que a falta de números oficiais mal disfarça: o dos professores vítimas de violência. Apesar da escassez de dados, um dos poucos levantamentos feitos em Minas, pela Secretaria de Estado de Defesa Social com base em boletins de ocorrência gerados em Belo Horizonte, mostra que os episódios de agressão dobraram desde o ano passado em unidades da capital, qualquer que seja o ambiente escolar considerado. Apesar de assustador, o indicador não reflete a realidade, pois na maior parte dos casos os ataques não são denunciados à polícia. Helena foi uma das vítimas dessa escalada. A educadora passava a matéria para os estudantes, quando foi surpreendida pela fúria de um aluno sob efeito de drogas [...] A presidente do Sindicato Único dos Trabalhadores em Educação de Minas Gerais, Beatriz da Silva Cerqueira, sustenta que a entidade é frequentemente acionada por vítimas de ameaça ou agressão, mas reclama que o poder público prefere "abafar os casos e tratá-los individualmente". "O que acontece, na maioria das vezes, é apenas uma suspensão do aluno, que posteriormente continua na escola, ameaçando aquele ou outro professor" [...] A mesma reclamação tem Antônia Alexandre Nogueira, professora do município de Cláudio, no Centro-Oeste mineiro, agredida este mês por um aluno. Depois de ter uma costela partida após um empurrão de um adolescente de 15 anos, a professora teme ser obrigada a encará-lo novamente (Menezes, 2010, s. p.).

Na reportagem acima, o corpo menino-aluno-guerreiro é constituído como algo que assusta e com o qual as autoridades políticas não estão sabendo lidar. No entanto, em meio a uma produção intensa de corpos guerreiros no currículo, discursos concorrentes também são

1260 Educação \& Realidade, Porto Alegre, v. 38, n. 4, p. 1243-1266, out./dez. 2013. Disponível em: <http://www.ufrgs.br/edu_realidade> 
produzidos. Um discurso ético circula constantemente no currículo, em concorrência com a produção do corpo guerreiro.

Profissional da escola - Cada um de vocês aqui tem que assumir o que faz e respeitar os colegas. Eu estou falando coisas importantes para a vida de vocês. Eu não quero mais ver vocês brigando um com o outro (Reis, 2011, p. 109).

Profissional da escola - Para mim, escola era um lugar de respeito. Aí eu pensei: bom, eu vou ter que melhorar essa convivência deles. O trabalho era o de fazê-los conseguirem enxergar o colega, respeitar o outro, saber que o outro depende de mim e que eu dependo do outro (Reis, 2011, p. 109).

Por meio desse discurso ético, é constituída a posição de sujeito aluno/a-respeitador/a-solidário/a. Essa posição está presente, também, nas Proposições Curriculares para o $2^{\circ}$ Ciclo da Secretaria de Educação da Prefeitura de Belo Horizonte (2009), onde se sugere trabalhar com os/as alunos/as a solidariedade, a empatia e o respeito ao outro. No currículo pesquisado, variadas práticas de produção do/a aluno/arespeitador/a-solidário/a estão presentes, dentre elas, o Projeto Pipoca, em que alunos/as assistem a filmes e, posteriormente, debatem temas relacionados às relações sociais; o Projeto Amizade, em que alunos/as ouvem músicas, fazem desenhos e debatem sobre as relações entre eles/ as.

Profissional da escola - Vocês lembram que eu falei pra vocês que a amizade é a coisa mais importante?

Omar - Mas e se os outros não gostar da gente?

Profissional da escola - Mas se você é um menino alegre, um menino que ajuda, que sabe se comportar bem... Eu tenho uma amiga que eu conheço desde os sete anos... (Reis, 2011, p. 110).

Profissional da escola - Essa turma está precisando respeitar um ao outro. Eu estava observando lá na educação física, as meninas brincando e os meninos atrapalhando. Eles, em vez de estar fazendo amizade, que é uma amizade pro resto da vida não... eles ficam brigando (Reis, 2011, p. 110).

Em concorrência com a produção de corpos guerreiros, circula, também, no currículo investigado, um discurso sobre direitos humanos:

Profissional da escola - Ninguém tem o direito de bater em ninguém na escola. É direito de alguém fazer isso com o colega? Ninguém vem à escola para apanhar, ninguém vem à escola pra bater (Reis, 2011, p. 110).

Ainda concorre com a produção da posição de sujeito meninoaluno-guerreiro, discursos que demandam o/a aluno/a-disciplinado/a.

Educação \& Realidade, Porto Alegre, v. 38, n. 4, p. 1243-1266, out./dez. 2013. 1261

Disponível em: <http://www.ufrgs.br/edu_realidade> 
A Constituição de Corpos Guerreiros em um Currículo Escolar

Profissional da escola - Conversando com o Marlan, nós chegamos à conclusão de que nós vamos fazer combinados do que é permitido e o que não é permitido em sala de aula. E se fizer uma vez só, já vai lá pra baixo e vai ter suspensão. Vocês vão assinar, os pais vão assinar, porque na hora que tiver suspensão, não vai poder falar "Ah! Eu não sabia..." Eu não vou aceitar briga nem em sala nem nas dependências da escola. Briga não resolve nada. A gente resolve é conversando. Estilingue não pode. Estilingue é uma arma. Brincadeiras de bater o pé no colega, de empurrar o colega. Brincadeiras de encostar, de empurrar, de chutar: não! (Reis, 2011, p.110).

Discursos de constituição do aluno/a-disciplinado/a são veiculados constantemente em concorrência com a produção da posição menino-aluno-guerreiro, demandando, assim, alunos/as que respeitam as regras escolares. Ainda como práticas discursivas concorrentes à produção desse ranking de gênero, a posição menino-aluno-estudioso é constituída de tal maneira que, aquele que não quer entrar na disputa por se tornar mais guerreiro, pode se posicionar como o fraco que gosta de estudar e que é inteligente.

Pesquisadora - O que você acha que devia mudar aqui nessa escola?

Aquiles - Devia mudar é... colocar os meninos fortes em outra escola, violentos... E os menino que são tipo fraco e inteligente, na escola em que estão.

Pesquisadora - E quem são os meninos fortes e violentos que você acha que poderiam ir pra outra escola?

Aquiles - Da sala ${ }^{19}$, tem muitos.

Pesquisadora - Eles brigam com vocês?

Aquiles - Brigam.

Pesquisadora - E você acha que os que são fortes e violen-

tos são inteligentes?

Aquiles - Tem alguns que não e outros sim. Mas a maioria dos que são forte não são inteligente.

Pesquisadora - É? E por que você acha que acontece isso? Aquiles - Por causa que eles não gosta de estudar. Gosta é de bater... gosta só de ficar batendo e de ficar jogando futebol (Reis, 2011, p. 110).

Nas enunciações acima, está presente a separação entre meninosalunos fortes, que costumam se envolver em brigas, que gostam de futebol e meninos-alunos considerados fracos e inteligentes, que gostam de estudar. A concepção divulgada é a de que, apesar de poderem estar presentes em uma mesma pessoa, essas características são, geralmente, próprias a dois tipos de meninos-alunos: os fortes, brigões, esportistas e os inteligentes, estudiosos. Assim, além dos discursos disciplinares, éticos e sobre direitos humanos, discursos de produção do menino-alunoestudioso estão presentes, também, no currículo pesquisado, de modo a concorrer com a produção de corpos guerreiros.

1262 Educação \& Realidade, Porto Alegre, v. 38, n. 4, p. 1243-1266, out./dez. 2013 Disponível em: <http://www.ufrgs.br/edu_realidade> 


\section{Considerações Finais}

Para a produção de corpos guerreiros, no currículo pesquisado, não são mais necessários militares na escola, nem leis ou regulamentos, como em outras épocas. Eles são constituídos de modos mais sutis, por meio de técnicas e estratégias de poder mais eficientes, que mobilizam o desejo e produzem a sensação de maior autonomia. As análises realizadas mostram como normas de gênero e uma tecnologia de ranking atuam, no currículo pesquisado, de modo a produzir a normalidade do corpo-menino-aluno forte, corajoso e agressivo e a anormalidade daquele que não materializa esses atributos. Atuam também para posicionar os corpos-meninos-alunos em uma ordem de habilidades guerreiras, o que os estimula a se tornarem cada vez mais guerreiros. Essa produção normativa e ranqueadora dos corpos-meninos-alunos não é divulgada apenas por práticas curriculares anteriormente planejadas por profissionais da escola mas também por variados discursos que circulam e se materializaram em atos, movimentos, materiais, utilização de equipamentos e de espaços pelos/as alunos/as.

Recebido em 04 de novembro de 2012 Aprovado em 17 de setembro de 2012

\section{Notas}

1 HOMEM-ARANHA 3. Trailer. Direção: Christopher Burian-Mohr, David F. Klassen, David Swayze E Dawn Swiderski. Produção: Avi Arad, Grant Curtis E Laura Ziskin. Roteiro: Alvin Sargent, Baseado Em Estória De Sam Raimi E Ivan Raimi E Nos Personagens Criados Por Stan Lee, Steve Ditko, David Michelinie E Todd McFarlaneFrase. EUA, Sony Pictures: 2007. 1 DVD (140 min.). Disponível em: <http://www.youtube.com/watch?v=lk_oerzPFuA\&feature=fvsr >. Acesso em: 24 fev. 2011.

2 MC Orelha. Faixa de Gaza. Disponível em: <http://www.youtube.com/ watch?v=Zjm80Lhjupc $>$. Acesso em: 24 fev. 2011.

3 ESTRADA, Joaquim Osório Duque; SILVA, Francisco Manuel da. Hino Nacional Brasileiro, 1922.

4 Os nomes dos participantes da pesquisa são fictícios.

5 Disponível em: <http://www.okjogos.com.br>. Acesso em: out. 2010.

6 Apesar do trabalho desse autor se referir à sociedade francesa, na década de 1980, alguns artigos têm sido publicados, no Brasil, utilizando o pensamento desse autor para análises da sociedade brasileira.

7 Apesar de Butler (2006) considerar que o aparato regulatório do gênero não é o mesmo que opera sobre outros tipos de normas, as concepções de homogeneização e individualização foucaultianas, relacionadas à norma (Foucault, 1987) são utilizadas nas análises aqui realizadas.

8 Para Foucault (1993), o governo é o ponto de contato da ação de técnicas de dominação - que se referem ao "modo como os indivíduos são manipulados e conhecidos por outros [com a atuação de técnicas de si, que se relacionam ao] modo como [os indivíduos] se conduzem e se conhecem a si próprios" (Foucault,1993, p 206).

Educação \& Realidade, Porto Alegre, v. 38, n. 4, p. 1243-1266, out./dez. 2013.1263 Disponível em: <http://www.ufrgs.br/edu_realidade> 
9 Em alguns momentos em que os atos de agressão se mostraram mais perigosos para as crianças envolvidas e não havia nenhum/a profissional da escola por perto, agi de maneira a proteger as crianças que estavam sendo agredidas.

10 Fui informada posteriormente por algumas crianças, que o menino-aluno agredido ficou deitado no chão por algum tempo, sem se mexer. Por isso, aquele que o agrediu estava dizendo que ele desmaiou.

11 A exemplo disso, temos o vídeo da música Bad Boys. Disponível em: <http:// www.youtube.com/watch?v=mT1KCiSLcHc $>$. Acesso em: 19 jun. 2011.

12 Confira o site da loja. Disponível em: <http://badboy.com.br>. Acesso em 19 jun. 2011.

13 Vídeo da loja virtual de produtos para meninos e meninas. Disponível em: <http://www.badboy.com.br/multi_sports.html>. Acesso em: 19 jun. 2011.

14 Vídeo da loja virtual de produtos para meninos e meninas. Disponível em: <http://www.badboy.com.br/fight_division.html>. Acesso em: 19 jun. 2011.

15 Propaganda de brinquedo para meninos. Disponível em: <http://www.you-

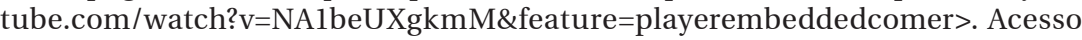
em: 19 jun. 2011 e em: <http://www.youtube.com/watch?v=NAlbeUXgkmM\& feature=related $>$. Acesso em: 19 jun. 2011.

16 Grand Theft Auto

17 MC Orelha. Faixa de Gaza. Disponível em: <http://www.youtube.com/ watch?v=Zjm80Lhjupc >. Acesso em: 24 fev. 2011.

18 Segundo informado na reportagem, os nomes utilizados são fictícios.

19 Denominação fictícia da sala.

\section{Referências}

ABATH, Daniel; CARVALHO, Nadja. A Comunicação Cotidiana em GTA IV: estudo de ambiências lúdicas na realidade virtual. Culturas Midiáticas, João Pessoa, v. 3, n. 2, jul./dez. 2010. Disponível em: <http://www.okara.ufpb.br/ojs/ index.php/cm/article/ view/11726/6766>. Acesso em: 14 mar. 2011.

BELO HORIZONTE. Secretaria Municipal de Educação. Desafios da Formação. Proposições Curriculares - Ensino Fundamental - 20. Ciclo, Belo Horizonte, 2009.

BUTLER, Judith. Problemas de Gênero: feminismo e subversão da identidade. Rio de Janeiro: Civilização Brasileira, 2003.

BUTLER, Judith. Deshacer el Género. Buenos Aires: Paidos, 2006.

CARVALHAR, Danielle Lameirinhas. Identidades Generificadas no Currículo da Educação Infantil: entre princesas, heróis e sapos. 2009. 148 f. Dissertação (Mestrado em Educação) - Programa de Pós-Graduação em Educação, Universidade Federal de Minas Gerais, Belo Horizonte, 2009.

CASTRO, Celso. In corpore sano: os militares e a introdução da educação física no Brasil. Antropolítica, Niterói, n. 2, p. 61-78, mar. 1997. Disponível em: <http:// cpdoc.fgv.br/ producaointelectual/arq/458.pdf $>$. Acesso em: 14 mar. 2011.

CASTRO, Edgardo. Vocabulário de Foucault: um percurso pelos seus temas, conceitos e autores. Tradução de Ingrid Muller Xavier; revisão técnica de Alfredo Veiga-Neto e Walter Omar Kohan. Belo Horizonte: Autêntica, 2009.

CORAZZA, Sandra. O que Quer um Currículo? Pesquisas pós-críticas em educação. Petrópolis: Vozes, 2001.

1264 Educação \& Realidade, Porto Alegre, v. 38, n. 4, p. 1243-1266, out./dez. 2013.

Disponível em: <http://www.ufrgs.br/edu_realidade> 
DAL'IGNA, Maria Cláudia. Desempenho Escolar de Meninos e Meninas: há diferença? Educação em Revista, Belo Horizonte, n. 46, p. 241-267, dez. 2007.

DORNELLES, Priscilla Gomes. Distintos Destinos? A Separação entre Meninos e Meninas na Educação Física Escolar na Perspectiva de Gênero. 2007. 156 f. Dissertação (Mestrado em Educação) - Programa de Pós-Graduação em Educação, Universidade Federal do Rio Grande do Sul, Porto Alegre, 2007.

EHRENBERG, Alain. O Culto da Performance: da aventura empreendedora à depressão nervosa. Tradução de Pedro Bendassolli. Aparecida: Ideias \& Letras, 2010.

FERRARI, Anderson. "O que é Loba??? É um Jogo Sinistro. Só pra quem for Homem..." - Gênero e Sexualidade no Contexto Escolar. In: REUNIÃO ANUAL DA ANPED, 30., 2007, Caxambu/ MG. Anais... Caxambu: ANPED, 2007. Disponível em: <http://www.anped.org.br/ reunioes/30ra/ trabalhos/GT23-2817--Int. pdf $>$. Acesso em: 13 maio 2009.

FOUCAULT, Michel. Vigiar e Punir. 32. ed. Petrópolis: Vozes, 1987.

FOUCAULT, Michel. Verdade e Subjetividade. Revista de Comunicação e Linguagem, Lisboa, n. 19, p. 203-223, 1993.

GADELHA, Sylvio. Biopolítica, Governamentalidade e Educação: introdução e conexões a partir de Michel Foucault. Belo Horizonte: Autêntica, 2009.

MENEZES, Nayara. Dobra o Número de Agressões a Professores nas Escolas de BH. Estado de Minas, Belo Horizonte, 28 nov. 2010. Disponível em: <http:// www.em.com.br/app/noticia/gerais/2010/11/28/interna_gerais,195058/dobrao-numero-de-agressoes-a-professores-nas-escolas-de-bh.shtml>. Acesso em: 12 dez. 2010.

MISKOLCI, Richard. Teoria queer e a questão das diferenças: por uma analítica da normalização. In: $16^{\circ}$ CONGRESSO DE LEITURA DO BRASIL, Campinas, 2007. Disponível em: <http://www.alb.com.br/anais16/prog_pdf/prog03_01. pdf>. Acesso em: 09 jul. 2009.

OLIVEIRA, Pedro Paulo de. A Construção Social da Masculinidade. Belo Horizonte: Editora UFMG, Rio de Janeiro: IUPERJ, 2004.

REIS, Cristina d'Ávila. Currículo Escolar e Gênero: a constituição generificada de corpos e posições de sujeito meninos-alunos. 2011. 154 f. Dissertação (Mestrado em Educação) - Programa de Pós-Graduação em Educação, Universidade Federal de Minas Gerais, Belo Horizonte, Minas Gerais, 2011.

ROSE, Nikolas. Como se Deve Fazer a História do Eu? Educação \& Realidade, Porto Alegre, v. 26, n. 1, p. 33-58, jun./jul. 2001.

SILVA, Tomaz Tadeu. O Currículo como Fetiche: a poética e a política do texto curricular. Belo Horizonte: Autêntica, 2006.

SOUSA, Eustáquia Salvadora de. Meninos à Marcha! Meninas à Sombra! A História do Ensino da Educação Física em Belo Horizonte. 1994. 266f. Tese (Doutorado em Educação) - Programa de Pós-Graduação em Educação, Faculdade de Educação, Universidade Estadual de Campinas, Campinas, 1994.

SOUZA, Eloiso Moulin; CARRIERI, Alexandre Pádua. A Analítica Queer e seu Rompimento com a Concepção Binária de Gênero. Revista de Administração Mackenzie Online, v. 11, n. 3, p. 46-70, 2010.

TELLES, Edna de Oliveira. Significados de Gênero no Cotidiano Escolar de uma Escola Pública Municipal de São Paulo. In: REUNIÃO ANUAL DA ANPED, 27., 2004, Caxambu/MG. Anais... Caxambu: ANPED, 2004. Disponível em: <http:// www.anped.org.br/reunioes/27/ ge23/ p233.pdf>. Acesso em: 14 maio 2009.

Educação \& Realidade, Porto Alegre, v. 38, n. 4, p. 1243-1266, out./dez. 2013.1265

Disponível em: <http://www.ufrgs.br/edu_realidade> 
Cristina d'Ávila Reis é mestre em Educação e Graduada em Psicologia pela Universidade Federal de Minas Gerais (UFMG).

E-mail: cristinadavilareis@gmail.com

Marlucy Alves Paraíso é professora Associada da Faculdade de Educação da Universidade Federal de Minas Gerais (UFMG) e do Programa de Pósgraduação Conhecimento e Inclusão Social da UFMG. É Pesquisadora 1D do CNPQ e Coordenadora do Grupo de Estudos e Pesquisas sobre Currículos e Culturas (GECC) da FAE/UFMG.

E-mail:marlucyparaiso@gmail.com 